[Dickie, J. (2008). Pasifika Students, Literacy As Social Practice, and the Curriculum. New Zealand Annual Review of Education, 17, 107-124]

\section{Pasifika Students, Literacy As Social Practice, and the Curriculum}

\section{JOHN DICKIE}

\section{Abstract:}

Ministry of Education guidelines for primary teachers increasingly emphasise literacy as social practice, and with growing diversity in schools, the Ministry advocates that teachers may help reduce disparity in achievement by making connections between students' out-of-school and school literacies. However it may be difficult for teachers to address this due to the Ministry's expectation of more detailed literacy skills to be acquired by specific levels of schooling, and the expectation of more detailed assessment. This article offers examples of out-ofschool literacies from a doctoral study which investigated literacy as social practice in family, church and neighbourhood sites as described by Year 7 and 8 Pasifika students. It raises the question as to whether existing assessment approaches and teacher knowledge are sufficiently broad to encompass literacy as social practice, considering the diverse literacy experiences students bring with them to school.

$\mathrm{T}$

he year 2007 saw the publication of The New Zealand Curriculum (Ministry of Education, 2007b) for primary and secondary schools and the introduction of the new literacy handbook Effective Literacy Practice in Years 5 to 8 (Ministry of Education, 2006). In the Effective Literacy Practice (ELP) handbooks for primary teachers, the Ministry of Education $(2003,2006)$ advocates a sociocultural perspective of literacy learning and teaching for the classroom, and in recognition of the increasing diversityin New Zealand classrooms, it suggests that teachers make links to students' own out-of-school literacy practices. This article describes the developments that led to the present Ministry requirements for literacy for primary teachers (of English) and suggests that these offer a dual perspective which may present teachers with a dilemma.

\section{John Dickie}

The Ministry of Education $(2003,2006)$ wants to reduce disparity in achievement for Pasifika and other students and expects teachers to be able to draw on strengths from students' cultural and linguistic backgrounds to help address this. The article discusses the extent to which the Ministry provides guidelines to teachers to help them achieve this, and considers the concept of "incorporation" which has been identified (McNaughton, 2002) as an appropriate means of enabling teachers to help students make links between their out-of-school practices and the curriculum requirements of school. A brief outline of a study (Dickie, 2008) considers what can be learned when this guidance is followed, and students' social and cultural uses of literacy in family and community settings are investigated. An obvious way to link out-of-school and school practices is for students to be taught in their Pasifika language at school, and this is also discussed.

However, parallel to these recommendations for teachers, the Ministry documents give more specific guidelines about literacy skills to teach, and the expected levels of attainment, while requiring more assessment of student achievement. The second section of the article describes these increasingly detailed guidelines and considers whether the Ministry of Education's definition is sufficiently broad to include the interpretations of literacy as social practice.

\section{Growing Diversity in New Zealand Schools}

Pasifika students represent a growing diversity of ethnicity in New Zealand schools, making up 9.1 percent of the primary and secondary school population in New Zealand in $2006 .{ }^{1}$ An increasingly significant issue for New Zealand educators and the wider community is that of literacy achievement of primary school students who come from a Pasifika background. Although New Zealand students in the compulsory education sector perform well in comparison to their peers in other countries, lower test scores for Pasifika and Māori students have been a cause for concern (Crooks \& Flockton, 2005; Crooks, Flockton \& White, 2007; Flockton \& Crooks, 2003; Sturrock \& May, 2002), indicating a need to investigate ways in which literacy learning might be supported for these students in New Zealand classrooms.

\section{Increasing Emphasis on Literacy As Social and Cultural Practice}

The Ministry of Education's requirements for primary school literacy that are promulgated through The New Zealand Curriculum (Ministry of 
Education, 2007b), and supporting materials such as the teacher handbooks, increasingly show an interpretation of literacy as social and cultural practice. Successive Ministry of Education literacy handbooks for teachers have demonstrated an increasing emphasis on the need for teachers to make effective links to students' cultural backgrounds, and this seems appropriate considering the growing diversity of students in New Zealand classrooms. This approach is consistent with the work of Street $(1984,1995)$ whose ideological model of literacy concentrates on the specific social practices of reading and writing, recognising the culturally embedded nature of these. This model stresses the significance of social processes in the construction of meaning, and is therefore concerned with all the social institutions through which this takes place, not just the "educational" ones. Street writes that many representations of literacy assume it is a neutral technology that can be detached from specific social contexts, and it matches the view of literacy as a set of skills that are culture free. Street refers to this as the autonomous model.

The two most recent handbooks for literacy emphasise cultural links to students' backgrounds much more than the previous handbooks for teachers. Effective Literacy Practice in Years 1 to 4 (Ministry of Education, 2003) and Effective Literacy Practice in Years 5 to 8 (Ministry of Education, 2006) form a crucial component of the Ministry of Education's literacy strategy. In the foreword to the second, the Secretary for Education describes the text as "integral to the ongoing implementation of the Government's Literacy Strategy" (p. 6) and the texts are described as the key references for teacher professional development in Years 1 to 4 and 5 to 8 respectively. Other important support materials for teachers include The Literacy Learning Progressions (Draft for consultation) (Ministry of Education, 2007a) and the curriculum exemplars for English (<www.tki.org.nz/r/assessment/exemplars/eng/ >).

The handbooks argue that one way to raise the achievement of Pasifika and other students of diverse backgrounds is to understand their out-of-school literacies which are situated in their families and communities. This would involve examining how and where students use literacy in meaningful contexts, and considering the curriculum and the teachers in the various sites. However, The New Zealand Curriculum released in 2007 (Ministry of Education, 2007b) offers little guidance on making these out-of-school links. Under a heading of effective pedagogy it states that "Learning is inseparable from its social and cultural context" and it advocates that teachers make connections to students' prior learning and experience, specifying "home practices" (p. 34). The curriculum states that the transition into school from early childhood education is supported when the school "builds on the learning experiences that the child brings with them" (p. 41).

Both ELP handbooks explain literacy development as the socialisation model where learners construct meaning within the social settings of home, school and community. Effective Literacy Practice in Years 5 to 8 states "Social and cultural practices in fact shape all learning, and learners' literacy development is shaped by their interactions with those around them" (Ministry of Education, 2006, p. 20). It also states "Because each student's literacy learning is grounded in the culture of their family and community, teachers need to become aware of the literacy practices of local families and to know how language is used in their students' homes" (p. 50). However, the handbook cautions teachers that generalisations about groups of students may be disadvantageous, as individual students who come from similar cultural and linguistic backgrounds can differ greatly in the knowledge and experience that they bring to the classroom.

The handbooks attempt to avoid a deficit view of diversity and argue that diversity in the classroom can be regarded by teachers as a rich resource rather than a difficulty. In order to share this perspective, teachers will need to know their students and their communities well. In addressing knowledge of literacy learning, both ELP texts state that teachers need to consider cultural engagement:

Every learner (like every teacher) views literacy tasks through a cultural "lens" because most of the prior knowledge, experiences, and values that a learner brings to their learning arise from their cultural and linguistic background. Effective teachers recognise and build on their students' cultural knowledge and values in order to engage them in literacy learning. This is particularly important in classrooms where the students come from diverse backgrounds, especially where their backgrounds differ from the teacher's. (Ministry of Education, 2006, p. 23)

While the handbooks emphasise that family and community literacies should be valued and built on by the school, it is not their intention to explain in any detail how to include students' out-of-school literacies in school programmes. However, a suitable strategy that enables transfer of learning between out-of-school and school sites is described by McNaughton (2002) as "incorporation": 
Effective connections for the learner happen when the activities in an (often unfamiliar) instructional programme incorporate features of some familiar expertise that up until then have been situated in out-of-school activities. Transfer of learning occurs as a result of this incorporation. (p. 27)

This strategy of building on to what is familiar has been used to make meaningful connections for students in widely different settings. For example, a study that investigates its use for Samoan students in New Zealand has been conducted by Amituanai-Toloa (2005), who explored the effects of incorporating students' out-of-school activities in improving comprehension in six Samoan bilingual classrooms in South Auckland. McNaughton (2002) argues that for children from culturally and linguistically diverse backgrounds who are beginning school, the "meeting of minds" (p. 14) between teacher and learner is vitally important for effective literacy teaching. This can be achieved through "enhancing the multitude of sites that learners and teachers have available to them in which to make connections" (p. 26). He explains that effective connections can be made for the learner when the class programme incorporates features in which the child has developed expertise in out-of-school settings. He writes "transfer of learning occurs as a consequence of this incorporation - bridges between the familiar and the unfamiliar can be made by both the learner and by the teacher" (p. 27). However, incorporating out-of-school knowledge and expertise may not match the curriculum or pedagogy of the school. Therefore, what McNaughton terms a "discrimination learning" is required (p. 28) so children become aware to what extent their out-of-school knowledge is aligned with that of school.

\section{A View of One Community's Literacy Practices}

An insider perspective of out-of-school literacy where the participants were Pasifika students has been investigated by Dickie (2008). The participants were 14 students aged 11 and 12 years (mostly Samoan) who attended an inner city Catholic school, and the investigation sought their own perspective of how they appropriate knowledge about literacy as they collected information with cameras and journals on their own practices. The students' photos were used to elicit rich description in semi-structured interviews, and interview schedules were also used with students and the adults who represented the church to which the school was attached. The study used Cremin's (1976) concept of configurations of sites to consider how learning is mediated for students in different settings, while Rogoff's (1995) three planes of analysis provided a tool to examine students' participation as they acquired literacy in social and cultural activities. Each student is seen as an active participant on the personal plane which offers a view through their own eyes as they appropriate what they consider to be important in literacy. They are seen at the interpersonal level in guided participation with various others as teachers. For example in family sites their teachers included parents, grandparents, cousins and older siblings, while in church sites their teachers included priests and Sunday School teachers. At the community level, students are seen as apprentices learning the values, expectations and curriculum of their community. The findings illustrate how the students were socialised into particular practices that are contextualised in the sites of family, church and neighbourhood, and reveal that for the students there was both overlapping of values and conflict between their sites of literacy practice. It is important that teachers are aware of these complementary and conflicting features to enable them to appreciate the complexities their students face as they choose their paths among two cultures. This knowledge may enable teachers to incorporate aspects of out-of-school literacy into school practice and to draw on those people in the students' backgrounds who may facilitate students' literacy acquisition.

One of the major themes of literacy practice that emerged for these 11- and 12-year olds was the uses of literacy for the purpose of entertainment and pleasure, including the fields of popular culture. Children's popular culture is described by Marsh and Millard (2000) as overlapping that of adults in the broad fields such as music, sport, computer software, books, magazines and film. While the students may have less freedom in regard to some other literacy practices, those related to popular culture are particularly interesting as they illustrate what the students have made their own, and these could be used by teachers to make effective connections to school literacy. The students described many conventional uses of literacy such as reading books and magazines, but the less conventional uses which were related to computer use, popular music and reading fashion labels are described in the following section.

All seven boys and four of the girls said they used PlayStation computer games, with several boys but no girls describing it as a favourite spare time activity. Their uses of reading and writing included how to navigate onscreen, which involved following the instructions of 
the menu and understanding the visual symbols and images of the games. It also involved reading books of instructions and reading DVDs and magazines associated with the games. The students described the value of reading the written instructions known as "cheats" that are used to attain higher levels in the game, and they explained that they purchased these from certain shops or downloaded them from the Internet. Many of the skills for computer games were learned from peers, older siblings or cousins. A clear example of a useful link to a student's interest in popular culture and to identity construction was provided by one boy who offered limited responses to the questions and to his photos, but who became animated, articulate and motivated when describing his PlayStation games and how he read the books of instructions for them.

For some students there was conflict between popular culture on the one hand and family and religion on the other, this being in relation to the violence in some of the computer games and also to the amount of time students spent playing the games. One aspect of the boys' computer game choices was their preference for violent games, which seems to form an interesting contrast to their religious identity with its strong connections to Sunday school and church. The enthusiasm for violent games also conflicted with the views expressed by some of the adults in the students' community. However, this preference was not shared by all, as two boys spoke out strongly against violence in the games.

Music also forms part of children's popular culture (Luke, 1997; Mahiri, 2000; Marsh \& Millard, 2000), and uses related to music were selected by several of these students to illustrate their out-of-school literacies. They explained that they read the words on the CD covers, downloaded and read the words of songs from the Internet, and frequently also wrote out the words of songs. Students' descriptions indicated that the most common conflicts of values between the sites for literacy use were those related to popular culture, and they occurred between the sites of family, church and school on the one hand and neighbourhood sites on the other, as well as within family sites. This is illustrated by the discussion with two boys who chose a Gangsta rap singer to represent their taste in music. The values of this genre of hip-hop seem to contrast strongly with the values of some of the educative institutions which mediated the students' learning. Each boy had selected PlayStation as his favourite spare time activity and they both liked fighting games. Both said that they attended church regularly and read the Bible at home. One boy illustrated this with a photo which showed him reading the Samoan Bible while another showed him reading a prayer book which he said he did every morning before going to school. While young people's interest in popular culture provides many opportunities for teachers and students to link out-of-school and school literacies, teachers need to be aware of potential conflicts of values for students, and they must select carefully or guide the students' selection when aspects of popular culture are to be incorporated into school literacy.

A literacy use which seems simple and obvious but which is of great interest to young people is that of attaching value to certain clothing labels. Clothing and sports accessories form part of children's popular culture (Marsh \& Millard, 2000), and several students in this study selected brand name fashion labels as descriptions of their out-of-school literacy use. While the labels described by students may contain only one or two words and perhaps a logo, it is what is signified that is important. Wearing clothing that displays a particular label is about sharing identity and being part of a particular community. Much of the students' interest was in fashion that was connected to American sports teams' names and American sports stars, and the students were clear in their own views of which labels were "cool". According to Kenway and Bullen (2001), brand-name fashions are instantly recognised by young people as codes of identity, and the clearest example of this was the references made by students to one brand of shoes, Chuck Taylor All-Stars which are produced by Converse. No other label was mentioned as often or with such enthusiasm as "Chucks", and both boys and girls demonstrated quite detailed knowledge of this brand's features and explained why they valued it as a code of identity.

\section{Sites for Church Literacy}

The data from the study (Dickie, 2008) indicate that the church and Sunday school were important educative sites for literacy in the lives of these students, and through their strong connections with the sites of family and school were powerful mediators of students' literacy practices. The majority of the students attended Sunday school. As well, for many students the home was a site where church-connected literacy took place and a very strong connection existed between these family sites and the sites of church and Sunday school. The practices in these sites were closely interconnected, having similar values and pedagogy. For most of the students both English and Samoan languages were used 
in the sites of church, Sunday school and home. Samoan was also taught in the school to some classes and students used Samoan in the playground.

The findings illustrate the significance to the participants of the Bible, both the Samoan and the English versions, and their community's literacy practices which are linked to the Bible. The students' uses of reading and writing illustrate that their community valued certain cultural practices in literacy and the students explained how they were apprenticed into these practices. The community valued having access to the Word of God through the written Word being accurately read aloud to an audience and also valued people being able to read the Word of God directly for themselves. Another important aspect was the maintenance of the Samoan language through religious practices.

There were many examples of literacy in family sites that supported religion. The students described reading the English and Samoan Bibles as part of family and individual worship as they also did reading family and individual prayers. Many students described how they learned tauloto (memory verses) for White Sunday and how their families supported this memorisation of Bible passages. Examples of reading in church sites included reading Bible stories and discussing them in a group as in guided reading at school, reading prayers, reading the words of hymns and songs on a screen and in books. Like the reading uses, the writing uses illustrate particular social practices within meaningful contexts in both the English and Samoan languages. While some of these are independent writing activities, most of them involve guided participation through interaction with a teacher. Writing activities that are taught in the Sunday school included writing stories, answers to questions, cloze exercises, graphic organizers where students put information in a diagram, writing dictation, writing a summary, and answering written questions in exams and tests.

The examples of popular culture and church literacy described by the students illustrate their social practices of reading and writing and are consistent with Street's (1984) ideological paradigm in illustrating the culturally embedded nature of their community practices in literacy.

\section{Effective Connections: Using Pasifika Languages in Schools}

It was clear from both student and adult participants (Dickie, 2008) that maintenance of the Samoan language was highly valued by this community and Samoan was used (as well as English) in family, church and school sites. An obvious way for schools to link home and school literacy practices and to address equality of opportunity is for students to be taught at school in their home language. The New Zealand Curriculum (Ministry of Education, 2007b) provides for the teaching of Pasifika languages in a new eighth learning area named Learning languages. It acknowledges the special place of Pasifika languages in New Zealand "because of New Zealand's close relationships with the peoples of the Pacific" (p. 24). It requires that schools with Year 7 to 10 students "should be working towards offering students opportunities for learning a second or subsequent language" (p. 44), and it may be that schools choose to teach in a Pasifika language. The significance of connectedness with their own community is stressed by those who write in support of Pasifika languages being taught in schools. Strong arguments have been advanced for the teaching of Pasifika languages in New Zealand schools by Irwin (1988), Spolsky (1988), HunkinTuiletufuga (1996,2001), May, Hill and Tiakiwai (2004), and Taumoefolau, Starks, Bell and Davis (2004). While the peoples of the various Pacific nations may be viewed at times by other New Zealanders as one homogeneous group, they each have their own distinctive cultures, a point made by Hunkin-Tuiletufuga (2001) who argues that:

each of the Pacific languages has a centrally important role to play in keeping Pacific cultures and associated identities alive, particularly in migrant enclaves such as those in New Zealand. Each language embodies values, knowledge and understandings that give meaning, structure and purpose to the social life of its users... We are able to build a cultural system in our own Pacific language and through which the world is moderated... Our cultural domains, and the value systems that underlie and influence our social systems, are embodied in our languages. (pp. 197-198)

May, Hill and Tiakiwai (2004) write that there are few studies in New Zealand that address Pasifika bilingual education directly. However, Hampton (1992), May (1994) and McCaffrey and Tuafuti (1998) (all cited in May, Hill \& Tiakiwai, 2004) illustrate positive results in English for students involved in bilingual programmes with Pasifika languages. There are cultural and social benefits to learning two languages. May, Hill and Tiakiwai argue that bilingual students have certain advantages over monolingual students, explaining how bilingual learners tend to develop greater linguistic and syntactic awareness and demonstrate more divergent thinking.

However, in spite of support in the community there is very limited use of Pasifika languages in New Zealand schools. At July 2006 a total 
of 32 primary and secondary schools offered a Pasifika language as the medium of instruction for more than three hours a week, involving a total of 2,513 students. ${ }^{2}$ A factor that may make this more difficult to achieve is the small number of teachers who identify as Pasifika, with only three percent of primary teachers and two percent of secondary teachers identifying as being Pasifika, in comparison with 9.1 percent of students who identify as being from a Pasifika background. Around 400 primary and secondary teachers identified in 2004 that they had taught students in a Pasifika language, with nearly three quarters of these teaching in Samoan. ${ }^{3}$

\section{Increased Emphasis on Skills, Levels and Assessment}

While the argument is made for teachers to recognise diversity and make connections for students, this may be difficult for them as curriculum requirements become more detailed with demands for more assessment. Carpenter (2001) writes that when the Curriculum Framework (Ministry of Education, 1993) was first published it seemed to be liberal and permissive. However, since then the curriculum statements and support material have made the structures for teachers more prescribed and the autonomy of teachers more restricted. What the New Zealand curriculum now represents seems to be parallel demands. On the one hand there are the skills required, and on the other, the need to make effective links to students' social and cultural practice. While these demands may not necessarily exclude each other, achieving the links to out-of-school practices is made more difficult when education is increasingly driven by assessment, if the assessment is concerned with school literacy practices only.

In New Zealand the production of supporting handbooks and documents such as the English writing, oral and visual language exemplars mean that teachers are required to teach and assess increasingly complex skills and consequently may have less freedom to teach more learner-centred programmes. The more the official curriculum becomes described as levels and skills, the more difficult it becomes for teachers to incorporate students' out-of-school social and cultural uses of literacy from their family and community settings. A further difficulty for teachers would be the amount of time required to find out and understand the implications for their teaching and assessment of these literacies in school programmes. The increasing demands on assessment in education are challenged by Carpenter (2001), who suggests that New Zealand is reflecting education systems overseas where global political and economic structures have influenced education systems. She cautions that "Each new publication or idea has the potential to move curriculum further towards rigidity and conformity, using the argument that teachers require or should have imposed on them, 'guidelines'" (p. 130).

Schools are now required to provide more detailed information on student achievement to the Ministry of Education with the Education Standards Act of 2001 (Ministry of Education, 2005), expanding the type of information that schools are required to gather on students, as well as electronic reporting of statistical data from schools. In addition, changes introduced to school charters require goals for improved student achievement, and annually updated improvement targets. The choice of tools for assessment is made by the staff of individual schools, who must assess and report to their Boards of Trustees on levels of literacy. The influential Report of the Literacy Taskforce (Ministry of Education, 1999) recommended a description of the knowledge, skills and attitudes for nine-year-old children for reading and writing. This led to the detailed indicators of reading and writing skills in the primary teachers' literacy handbook Effective Literacy Practice in Years 1 to 4 (Ministry of Education, 2003) (which show what children might be expected to have acquired after one year and four years at school) and the indicators for the end of Year 8 in Effective Literacy Practice in Years 5 to 8 (Ministry of Education, 2006).

If it is true that education is increasingly driven by assessment, it needs to be considered whether the assessment tools are restricted to school literacy only or whether they are relevant to the types of literacy that students use in out-of-school settings, and which teachers and students may want to incorporate into school programmes. The standardised assessment procedures that teachers may use to assess their students in literacy are listed in the ELP handbooks (Ministry of Education, 2003, pp. 59-60; 2006, pp. 59-60) with guidelines for the levels where some of these tools may be used. Examples include School Entry Assessment (Ministry of Education, 2001), Running Records (Ministry of Education, 2000), The Observation Survey (Clay, 2002), Assessment Tools for Teaching and Learning (asTTle) (Ministry of Education and the University of Auckland, 2003) and the Supplementary Tests of Achievement in Reading (STAR) (Elley, 2000).

While the new curriculum (Ministry of Education, 2007b) has been designed to be more easily understood than the previous one, with fewer achievement objectives, the English curriculum is detailed in its 
description of the required skills and knowledge for each of the eight levels. The curriculum is supported by the Literacy Learning Progressions (Ministry of Education, 2007a) which is a tool designed to "describe the knowledge and skills that students need to have developed at specific points in their schooling if they are to engage with the texts and tasks of the curriculum and make the expected progress" (p. 3). More specific guidelines on reading levels are offered than previously, with expected levels of reading given for the first three years of school. While the document states that in some places the progressions reflect the performance of most students at these points, it advises that in some other places they are aspirational. While there is brief mention in the introductory section on engaging and motivating students by making connections to their individual expertise and interests, the emphasis in the progressions themselves is very much on the skills of reading and writing, and links to students' out-of-school literacies are not reflected in the skills that are listed. They are illustrated by exemplars of student work and examples of texts that could be used at particular levels. If the knowledge, skills and assessment tasks are not relevant to the students' own lives, then what is taught and assessed may reflect Street's (1984) autonomous representation of literacy, in other words, skills as neutral technology which may be taught out of meaningful contexts, rather than his ideological interpretation which recognises the culturally and socially embedded practices of reading and writing.

\section{The Implications for Practice in Schools}

The parallel demands of the "official" literacy requirements for primary schools present a challenge to teachers of Pasifika and other students who are over-represented in the negative statistics that are derived from the official measures. The dual perspective in the Ministry of Education ELP handbooks and other documents emphasises the teaching of skills while at the same time stressing a social and cultural interpretation of literacy. This view of literacy as social practice seems highly appropriate in light of the changing demographics of New Zealand schools and the need to address disparities in literacy learning. Reading the handbooks can lead to the interpretation that the Ministry supports recognition of Pasifika and other students' own cultural uses of literacy, although they do not offer teachers specific information on how to achieve this. Clearly there is a need for teachers to have more information on this and also a need for the curriculum to be interpreted in a way that is flexible enough to suit learners from diverse backgrounds. An implication for schools is that New Zealand teachers who are largely monocultural and monolingual need to establish more equitable and focused relationships with the families and communities of their minority language students. There is also a strong argument for valuing, and using, Pasifika languages in schools.

To be effective, teachers need to know more than how their students use literacy; they need to develop an understanding of the overlapping values and pedagogy between the students' sites for literacy, so that those that match the school can be reinforced through school programmes. There is also a need for an acceptance that incorporation involves both student and teacher input. The students need to feel comfortable that they can build on what is familiar to them, and although the connections they make may not be familiar to the teacher, the teacher can acknowledge the students' expertise in this field.

An implication for practice in schools is that knowledge of students' out-of-school literacies may help teachers to challenge beliefs about how they assess their students' literacy and the tools they use to do this. Au and Raphael (2000) explain that "the ideological model reminds us that the literacy measured by achievement tests is but one among several literacies that students are learning. Students of diverse backgrounds often appear highly literate and accomplished when literacies other than those of the school are considered" (p. 173). With the increasing emphasis on assessment, the question needs to be asked whether school assessment tasks in literacy adequately reflect students' understandings of literacy or is there a danger that they are becoming decontextualised for many young people, in other words, the autonomous, culture-free skills described by Street (1984)?

The autonomous and ideological models do not necessarily set up a dichotomy, and Street suggests that in fact all models of literacy can be understood within an ideological framework. From his view, the autonomous model could therefore be seen as a subset within the ideological framework. This means that an ideological interpretation does not exclude the teaching of skills. The implication of this for the Pasifika students is that where possible school literacies and assessment of school literacies need to be relevant to Pasifika (and other) students by making connections to their interests and backgrounds. This may lead to more careful selection of how particular assessment tools are used (for example, by assessing students when they read or write about topics that reflect their out-of-school knowledge) or by balancing the more formal assessment with non-standardised and informal 
assessment procedures. An example of this might be the students and teacher jointly constructing criteria relating to those of popular culture texts in the classroom and using these criteria for self and peer assessment.

Literacy is recognised as part of one's cultural practices and this means that children can bring very different literacy experiences to reading and writing. However, if it is true, as Broadfoot (1996) suggests, that there is a "pervasive presence and overwhelming importance of formal assessment procedures in any form of mass education provision" (p. 19), it is difficult to see how teachers can include a very strong focus on literacy as social practice, because it cannot be assessed in that way. With this view of assessment being so important as a driver of education, there is a danger that teachers may focus too much on skills.

The question can be asked if the curriculum and support materials are sufficiently broad to encompass interpretation of literacy as social practice. This will depend a great deal on the individual teacher's knowledge of students' out-of-school literacy practices. It is a moot point whether just knowing about a student's background will assist a teacher to make a difference to the student's learning. However, knowing something of the literacy practices that students may experience in their homes and communities may bring recognition of how much they may miss if they do not know their students and communities sufficiently well. If teachers recognise that there are skills and social practices in literacy that are transferable from communities to school contexts they must develop a clear understanding of how these practices operate. This will be essential if students' out-of-school literacies are to be incorporated into classroom programmes in authentic ways.

\section{Notes}

1. Student numbers as at 1 July 2006, Education Counts.

$<$ http://educationcounts.edcentre.govt.nz/statistics/schooling/ pasifika-medium-education $>$.

2. Pasifika-medium education as at 1 July 2006. Education Counts. $<$ http://educationcounts.edcentre.govt.nz/statistics/schooling/ pasifika-medium-education $>$.

3. Teacher census, Education Counts

$<$ http://educationcounts.edcentre.govt.nz/themes/schooling/ teacher-census.html>

\section{References}

Amituanai-Toloa, M. (2005). Ua Malie Toa Ua Malie Tau. Students with silver tongues whip the tail: Enhanced teaching and learning of reading comprehension in Samoan bilingual classes. Unpublished DPhil thesis (Education), University of Auckland.

Au, K., \& Raphael, T. (2000). Equity and literacy in the next millennium. Reading Research Quarterly, 35(1), 170-188.

Broadfoot, P. (1996). Education, assessment and society: A sociological analysis. Buckingham: Open University Press.

Carpenter, V. (2001). Curriculum and the (re)production of education. In H. Carpenter, E. Rata, \& C. Rawlinson (Eds.), Theory in practice for educators (pp. 109-136). Palmerston North: Dunmore Press.

Clay, M. (2002). An observation survey of early literacy achievement (2nd ed.). Auckland: Heinemann.

Cremin, L. (1976). Public education. New York: Basic Books.

Crooks, T., \& Flockton, L. (2005). Reading and speaking assessment results 2004. Dunedin: Educational Assessment Research Unit, University of Otago.

Crooks, T., Flockton, L., \& White, J. (2007). Writing assessment results 2006. Dunedin: Educational Assessment Research Unit, University of Otago.

Dickie, J. (2008). An investigation of sites, uses and practices for literacy in the lives of Pasifika students. Unpublished DPhil thesis (Education), Victoria University of Wellington.

Elley, W. (2000). STAR: Supplementary test of achievement in reading for years 3, 4-6 and 7-9. Wellington: New Zealand Council for Educational Research.

Flockton, L., \& Crooks, T. (2003). Writing Assessment Results 2002. Dunedin: Educational Assessment Research Unit, University of Otago.

Hunkin-Tuiletufuga, G. (1996). A possible missing factor? The role of Pacific Islands languages in the education of Pacific Islands children in New Zealand. Proceedings of National Symposium 1996 Pacific Islands learning: The answers are within us (pp. 65-69). Wellington: Education Training and Support Agency.

Hunkin-Tuiletufuga, G. (2001). Pasefika languages and Pasefika identities: Contemporary and future challenges. In C. Macpherson, 
P. Spoonley \& M. Anae (Eds.), Tangata O Te Moana Nui: The evolving identities of Pacific peoples in Aotearoa/New Zealand (pp. 196-211). Palmerston North: Dunmore Press.

Irwin, K. (1988, August). The needs of Pacific Island students in school. Paper presented at the First Research into Educational Policy Conference, Wellington.

Kenway, J., \& Bullen, E. (2001). Consuming children. Buckingham: Open University Press.

Luke, C. (1997). Media literacy and cultural studies. In S. Muspratt, A. Luke, \& P. Freebody (Eds.), Constructing critical literacies: Teaching and learning textual practice (pp.19-49). Cresskill, NJ: Hampton Press.

Mahiri, J. (2000). Pop culture pedagogy and the end(s) of school. Journal of Adolescent and Adult Literacy, 44(4), 382-385.

Marsh, J., \& Millard, E. (2000). Literacy and popular culture: Using children's culture in the classroom. London: PaulChapman Publishing.

May, S., Hill, R., \& Tiakiwai, S. (2004). Bilingual/immersion education: Indicators of good practice. Final report to the Ministry of Education.

Hamilton: University of Waikato, Wilf Malcolm Institute of Educational Research.

McNaughton, S. (2002). Meeting of minds. Wellington: Learning Media.

Ministry of Education. (1993). The New Zealand curriculum framework. Wellington: Learning Media.

Ministry of Education. (1999). Report of the literacy taskforce. Wellington: Ministry of Education.

Ministry of Education. (2000). Using running records. Wellington: Learning Media.

Ministry of Education. (2001). School entry assessment. Wellington: Ministry of Education.

Ministry of Education. (2003). Effective literacy practice in years 1 to 4. Wellington: Learning Media.

Ministry of Education and the University of Auckland. (2003). Assessment tools for teaching and learning. Version 2. Wellington: Learning Media.

Ministry of Education. (2005). Education Standards Act. Wellington: Learning Media.
Ministry of Education. (2006). Effective literacy practice in years 5 to 8 . Wellington: Learning Media.

Ministry of Education. (2007a). The literacy learning progressions (Draft for consultation). Wellington: Learning Media.

Ministry of Education. (2007b). The New Zealand curriculum. Wellington: Learning Media.

Rogoff, B. (1995). Observing sociocultural activity on three planes: Participatory appropriation, guided participation, and apprenticeship. In J. Wertsch, P. Del Rio, \& A. Alvarez (Eds.), Sociocultural studies of mind (pp. 139-164). Cambridge: University of Cambridge.

Spolsky, B. (1988). Report on the Samoan language in the New Zealand educational context. Wellington: Department of Education.

Street, B. (1984). Literacy in theory and practice. Cambridge: Cambridge University Press.

Street, B. (1995). Social literacies: Critical approaches to literacy development, ethnography and education. New York: Longman.

Sturrock, F., \& May, S. (2002). PISA 2000: The New Zealand context. The reading, mathematical and scientific literacy of 15 year olds. Wellington: Learning Media.

Taumoefolau, M., Starks, D., Bell, A., \& Davis, K. (2004). The role of second language acquisition theory and practice in Pasifika language maintenance in New Zealand. In A. Bell, M. Berryman, F. Burgess, I Christensen, K. Davis, S. Farry et al. (Eds.), Language Acquisition Research: Papers presented at a Ministry of Education Forum held in 2003 (pp. 41-55). Wellington: Ministry of Education.

\section{The author}

John Dickie is a senior lecturer in English literacy in the Faculty of Education at Victoria University of Wellington.

\section{Acknowledgement}

The author would like to thank Dr Geraldine McDonald who assisted with this article by providing feedback on a draft. 